\title{
Implicit Theories, Epistemic Beliefs, and Science Motivation: A Person-Centered Approach
}

Jason A. Chen

College of William \& Mary, jachen@email.wm.edu

Follow this and additional works at: https://scholarworks.wm.edu/articles

Part of the Education Commons

\section{Recommended Citation}

Chen, Jason A., "Implicit Theories, Epistemic Beliefs, and Science Motivation: A Person-Centered Approach" (2012). Articles. 15.

https://scholarworks.wm.edu/articles/15

This Article is brought to you for free and open access by W\&M ScholarWorks. It has been accepted for inclusion in Articles by an authorized administrator of W\&M ScholarWorks. For more information, please contact scholarworks@wm.edu. 
Running head: IMPLICIT THEORIES AND EPISTEMIC BELIEFS

Implicit Theories, Epistemic Beliefs, and Science Motivation:

A Person-Centered Approach

Jason A. Chen

The College of William and Mary

Contact Information:

Jason A. Chen

The College of William and Mary

School of Education

PO Box 8795

Williamsburg, VA 23187-8795

Phone: (757) 221-6201

Fax: (757) 221-2988

jchen04@gmail.com 


\section{Implicit Theories, Epistemic Beliefs, and Science M otivation: A Per son-Centered Approach}

Two themes that figure prominently among both policy documents and academic research in science education are issues related to developing students' beliefs about their competence in science and advancing students' beliefs about the nature of scientific knowledge and knowing (e.g., Britner, 2007; Cleaves, 2005; Dweck, 2007; National Academy of Sciences, 2011; National Research Council, 2000, 2007). This body of literature points to the fact that, for American schools to produce scientifically competent and literate citizens, students must develop certain habits of mind such as building a sense of confidence in being able to succeed in science, developing resilience in the face of failures, and believing that scientific knowledge can change over time (National Academy of Sciences, 2011). These beliefs are especially important in science, where many students consider such subjects considerably more difficult than their other subjects (Dweck, 2007), and that science experiments are done merely to prove what people already know (Elder, 2002; Solomon, Duveen, \& Scott, 1994). Because beliefs oftentimes can predict academic outcomes just as well as factors such as previous achievement or standardized test scores (Bandura, 1997; Dweck \& Leggett, 1988; Hong, Chiu, Dweck, Lin, \& Wan, 1999; Pajares \& Kranzler, 1995; Qian \& Alverman, 1995; Robins \& Pals, 2002; Schommer, 1990; Stipek \& Gralinsky, 1996), these beliefs about science competence and the nature of scientific knowledge and knowing are the focus of the present study.

Although both beliefs about competence and beliefs about the nature of scientific knowledge and knowing are important, in the psychological literature, these two beliefs are typically studied separately, mostly because of researchers' desires to keep the constructs conceptually pure (Hofer \& Pintrich, 1997; 2002). However, Elby (2009) argued that educational psychologists should be wary of eliminating conceptions of ability from the 
definition of epistemic beliefs because doing so may "obscure rather than elucidate the content and cognitive structure of students' views" (p. 139). Schommer-Aikins (2004) also argued that the epistemic belief system is quite narrow in scope, and there is a need to study it embedded within other belief systems. In a similar fashion, Dweck and her colleagues have long argued that "[implicit theories of ability] and their related motivational variables hang together into a coherent meaning system. ... Motivation variables, rather than working in isolation, are repeatedly seen to work together to create favorable or unfavorable outcomes" (Dweck \& Molden, 2005). Yet, despite this meaning systems label, and despite Schommer-Aikins's call to investigate the ways in which epistemic beliefs are embedded within other systems, there has been no research exploring how these variables and frameworks "hang together" or configure to form individual patterns within students. There is also no research exploring how such patterns might be related to motivation and achievement.

Furthermore, despite acknowledging that such variables and frameworks operate simultaneously within individual people, a great majority of the research has been conducted from a variablecentered approach (e.g., regressions, path analysis), which describes how variables are related to other variables, on average. However, as Molden and Dweck (2006) noted, "by attempting to describe only the average, one runs the risk of describing nobody in particular" (p. 192). This point suggests that research questions concerning psychological phenomena often deal with a person as a unit of analysis (e.g., does facilitating a belief that scientific knowledge is constantly evolving relate to whether students like science more?). However, when researchers answer these research questions using techniques that assume that the sampleis the unit of analysis (variable-centered techniques), the findings can be misleading when applied to actual classroom practice (Kaplan, Katz, \& Flum, 2012; Molenaar \& Campbell, 
2009; Molenaar et al., 2011). For this reason, by using a person-centered approach (Bergman, Magnusson, \& El-Khouri, 2003) — one that assumes that there are many types or profiles of students among the larger population — both theory and practice may be advanced.

Therefore, three main objectives guided the present study. The first objective was to uncover the various student profiles that may exist among middle- and high school students using beliefs about the plasticity of intellectual ability and beliefs about the nature of science knowledge. This objective is in line with Schommer-Aikins's (2004) proposal to investigate how beliefs about the nature of knowledge and knowing and beliefs about innate ability interact with each other. It is also in keeping with the main goals of science education reform to target students' competence beliefs and beliefs about the nature of scientific knowledge (National Academy of Sciences, 2011; National Research Council, 2000, 2007). Because these different profiles are likely related to different motivational and achievement outcomes, the second objective was to examine whether these student profiles are related to science achievement, the types of goals that students pursue, and their science self-efficacy. Finally, because beliefs about the nature of knowledge and knowing, as well as conceptions of ability have been shown to differ as a function of demographic variables (Dweck, 1999; 2007; see Hofer \& Pintrich, 1997, 2002), the third objective was to explore whether the student profiles differed as a function of race/ethnicity, gender, and grade level.

\section{Theoretical Framework}

\section{Implicit Theories of Ability}

According to Hong, Chiu, Dweck, Lin, and Wan (1999), implicit theories of ability create a meaning system in which ability and effort are given disproportionate weighting — students with an incremental view of ability are apt to place more import on effort, whereas those with a 
fixed view of ability tend to place more weight on ability. Although both an incremental and a fixed theory of ability may orient students to view both hard work and innate ability as necessary for successful performance, students with an incremental view of ability are likely to view effort as the more important cause of their performance outcome (Dweck, 1999; Dweck, Chiu, \& Hong, 1995). In contrast, students with a fixed view of ability are likely to view innate ability as the more important cause.

Implicit theories can also be domain specific. Thus, some students may believe that their science abilities are a relatively stable entity while simultaneously believing that their abilities in social studies are increasable (Stipek \& Gralinsky, 1996). As Bandura (1997) observed, "conceptions of ability should not be viewed as monolithic traits that govern the whole of life. The same person may view ability differently in different domains of functioning" (p. 119). Although much research has investigated how implicit theories of ability operate within math classes, far less research has explored the construct within science classes. Yet, the implicit theory construct, along with all of its associated constructs, is likely useful for helping researchers and educators to better understand science motivation. As mentioned earlier, science is often construed as being more difficult than other subjects (see Dweck, 2007), and when students lose the desire to pursue science-related subjects, they often blame their lack of science ability as a main reason for leaving the field (National Academies of Science, 2011). Therefore, although the theoretical framework undergirding students' conceptions of ability is the same regardless of the academic context, these beliefs are perhaps more salient in science, as Dweck (1999) has argued that the effects of students' conceptions of ability do not become evident until students begin to struggle and run into obstacles. 
Implicit theories can also be primed or induced (see Dweck and Molden, 2005).

Therefore, although these beliefs typically do not change researchers have reported success in teaching students either a fixed or an incremental theory of ability in intervention studies (e.g., Aronson, Fried, \& Good, 2002; Blackwell, Trzesniewski, \& Dweck, 2007). When these conceptions of ability have been taught to students, results have indicated that the two belief systems lead to two different motivational and achievement outcomes (see Dweck \& Master, 2009 for a review). Because students' implicit theories of ability are fairly easily primed, some have argued that the implicit theory construct is likely a knowledge structure such that both the fixed and the incremental views are freely available to students at all times, but that people may prefer one belief over the other in particular contexts (see Anderson, 1995).

Finally, Dweck $(1999,2002)$ has argued that conceptions of ability develop at a very young age. Young children first become familiar with issues of "goodness" and "badness," which they may believe to be stable or malleable. As they get older and begin school, students develop an awareness that ability might be a quality about themselves (see Butler, 1998; Marsh, Craven, \& Debus, 1991; Stipek \& Daniels, 1988), and by around age 7-8 are interested in comparing their abilities and performance with others. By age 10-12, these beliefs about ability begin to form networks, or meaning systems, with other beliefs such as the value of effort as well as interest in particular subjects (see Butler, 1990, 1999; Dweck \& Leggett, 1988; Stipek \& Gralinski, 1991; Wigfield et al., 1997). Because this meaning system, with conceptions of ability at its root, only begins taking hold during early adolescence, it is not until students reach this age (e.g., 10-12 years old) that these beliefs about ability begin to predict academic outcomes. 
Goal orientations in Dweck's framework. Dweck and her colleagues (Dweck \& Leggett, 1988; Elliott \& Dweck, 1988) hypothesized that the differential patterns of behavior formed by the two conceptions of ability (i.e., fixed versus incremental) may be linked to the goals that students pursue while engaging in problem-solving activities. Dweck and her colleagues have found that students who believed that their abilities could be augmented tended to display mastery orientated behaviors such as pursuing tasks for the sake of learning. On the other hand, students who espoused the view that their abilities were static tended to display performance oriented behaviors such as either showing off how smart they are or choosing not to do a task altogether to avoid looking incompetent (Blackwell et al., 2007; Dweck \& Sorich, 1999; Dweck \& Leggett, 1988; Robins \& Pals, 2002).

Self-efficacy in Dweck's framework. A number of studies have suggested that, during an intervention, when students are primed to espouse an incremental view of ability, their confidence to perform a task does not diminish in the face of challenges (Jourden, Bandura, \&Banfield, 1991; Tabernero \& Wood, 1999). Because the above studies were experimental, and conducted in laboratory settings, Bråten and Olaussen (1998) explored these relationships in a more naturalistic setting. They found that an incremental view of ability significantly predicted strategy use, independent of self-efficacy, which Dweck (2002) cited as evidence that conceptions of ability may have a stronger impact on academic outcomes than do self-efficacy.

However, as Bandura (1997) has argued, conceptions of ability exert their effects not on achievement and behavior, but rather on the self-regulatory mechanisms that lead to achievement. In particular, "viewing ability as an inherent capacity lowers perceived selfefficacy, retards skill development, and diminishes interest in the activity. Although belief in the acquirability of talent is conducive to high personal development, it does not necessarily ensure 
it." (Bandura, 1997, p. 119). That is, a fixed view of ability leads to low self-efficacy, whereas an incremental view of ability is an important but insufficient component of robust high achievement. Sustained high achievement, according to Bandura, requires not only the belief that one's capacity can be expanded, but also the belief that one can muster all the resources in that person's repertoire of knowledge and skills to achieve a particular outcome (i.e., the selfefficacy to achieve at a high level over an extended period of time).

\section{Epistemic Beliefs}

Defining epistemic beliefs. In addition to implicit theories of ability, some researchers (e.g., Hofer \& Pintrich, 1997, 2002; Schommer, 1990) have argued that the beliefs that students hold about the nature of knowledge and knowing — epistemic beliefs — might also play a role in shaping students' motivation. Epistemic beliefs have received considerable attention in the past decade and describe people's beliefs about the nature of knowledge and knowing. Although individuals unconsciously hold these beliefs about knowledge and knowing, they are still influenced by them. For example, although a professor may frown upon students using the popular online reference Wikipedia as a source to justify a knowledge claim, students may see this source as a legitimate authority. Therefore, different people hold different beliefs about how knowledge can be justified, and as a result make different judgments about the credibility of particular sources. As informed consumers, people make judgments about how good a particular product is by reading reviews from Consumer Reports or from online magazines, thereby placing an amount of trust in the certainty of knowledge claims published in these journals. As learners in a classroom, students approach learning tasks in different ways depending on whether they see the material they are learning in their science classes, for example, as being connected to or isolated from what they learn in their other classes. 
Models of epistemic beliefs. Contemporary models of epistemic beliefs fall generally into one of two types: (1) unidimensional developmental models, and (2) models that consist of multiple, somewhat independently operating dimensions. By "independently operating," scholars typically imply that individuals can simultaneously possess varying levels of each of the multiple dimensions. For example, students may espouse the belief that scientific knowledge can only come from a knowledgeable elite (i.e., "real scientists"), but also simultaneously believe that there can be multiple "right answers" to a question in science. Developmental models such as Perry's (1970) model or Kuhn's (1991) model of argumentative reasoning characterize people by placing them on a continuum of beliefs that begins at more simplistic views (e.g., "dualism" in Perry's model or "absolutism" in Kuhn's model) to more sophisticated views (e.g., "relativism" in Perry's model or “evaluativism” in Kuhn's model).

Concerning domain-specificity, models that take more of a developmental perspective assume that beliefs about knowledge and knowing are domain general. This becomes apparent when one considers the questions that these researchers ask their participants. Rather than asking participants questions that require some content-specific knowledge, participants are asked very broad and general questions. Schommer's model of epistemological beliefs also initially presumed that these beliefs were domain general. However, this assumption has been called into question, especially with research showing that problem-solving and critical thinking are primarily domain specific (e.g., Chi, Glazer, \& Farr, 1988). The consensus within the field is that epistemic beliefs, although having some aspects of domain generality, are also domainspecific (for reviews see Hofer, 2006; Muis, Bendixen, \& Haerle, 2006). Following the recommendations of Hofer (2006) and Muis et al. (2006), the present study employed a measure specific to science. 
Measures of epistemic beliefs vary somewhat in their definitions and in the number of dimensions that are included. Although Hofer and Pintrich (1997) proposed that epistemic beliefs should be thought of in terms of the four core dimensions (simplicity, certainty, source, and justification of knowledge), others have used quantitative measures that include anywhere from three dimensions (Qian \& Alvermann, 1995) to five (Wood \& Kardash, 2002). As mentioned earlier, some of these dimensions assess constructs like beliefs about learning, teaching, or ability, which are not central to beliefs about knowledge and knowing. For this reason, findings concerning the relationships between epistemic beliefs and academic motivation vary depending on the instrument used to assess epistemic beliefs. In the present study, I followed the guidelines set forth by Hofer and Pintrich by assessing only the four core components of epistemic beliefs, thereby treating beliefs about knowledge and knowing as a separate construct from conceptions of ability.

\section{Relationship between implicit theories of ability and epistemic beliefs: The}

Embedded Systemic M odel. Researchers have begun to investigate the relationship between epistemic beliefs and implicit theories of ability (Bråten \& Strømsø, 2004; Chen \& Pajares, 2010; Hofer \& Pintrich, 1997; Schommer, 1990; Schommer, Crouse, \& Rhodes, 1992). For example, Bråten \& Strømsø, (2004) sought to discover the differential contribution of epistemic beliefs and implicit theories to the adoption of achievement goal orientations. Their results indicated that one dimension of Schommer's (1990) measure of epistemic beliefs (“quick learning") was a significant predictor of goal orientations, whereas implicit theories of ability were less predictive of goal orientations. However, the "quick learning" dimension is not traditionally considered a core dimension of epistemic beliefs. Rather, it is often thought of as more in line with conceptions of ability (see Hofer \& Pintrich, 1997). Furthermore, Bråten \& 
Strømsø found no significant correlations between the core components of epistemic beliefs (simplicity and certainty of knowledge, which are in fact epistemic) and goal orientations. This raises the question of whether the core components of epistemic beliefs really are more important predictors of achievement goal orientations as compared to implicit theories of ability. Clearly, more empirical evidence is needed to clarify the contribution of implicit theories of ability and the four core components of epistemic beliefs to the adoption of achievement goal orientations. Specifically, more research needs to be conducted whereby beliefs about the nature of knowledge and knowing are kept separate from constructs dealing with the nature of learning and ability, as outlined by Hofer and Pintrich.

On the other hand, even though beliefs about ability and beliefs about knowledge are separate constructs, these beliefs are likely related to one another. In Schommer's (1990) original model, she proposed that beliefs about innate ability were part of the same construct as beliefs about knowledge and knowing. However, after much debate, she significantly refined the model, which she called the Embedded Systemic Model (Schommer-Aikins, 2004). In this model, Schommer-Aikins broke from her original conception that beliefs about ability should be considered one dimension of epistemic beliefs, and instead recognized them as two different constructs. This separation allows researchers to model the interrelationships between these two beliefs. Using this Embedded Systemic Model, she presented a scenario positing that students who believe that knowledge can only come from a knowledgeable elite are more likely to view learning as passive, to believe that intellectual ability is fixed, and are less likely to question authorities in a classroom. This illustration suggests that beliefs about science knowledge and knowing "hang together" with conceptions of ability, in the same way that Dweck and Molden (2005) described how variables in Dweck's social-cognitive framework hang together. 
There are also theoretical reasons for why epistemic beliefs and implicit theories are linked together. Dweck, Chiu, and Hong (1995) observed that philosophers like Alfred North Whitehead posited two different worldviews that individuals embraced—one that viewed the world as a static world of unchanging objects and the other that viewed the world as a complex and dynamic system of interrelated processes (p. 282). The dimensions of epistemic beliefs include this idea of a static versus a dynamic view of scientific knowledge. Conceptions of ability, of course, also feature this concept of fixedness versus dynamism. Moreover, Hofer and Pintrich (1997) hypothesized that epistemic beliefs might function as a kind of implicit theory, which would give rise to particular achievement goal orientations, much in the same way that Dweck's implicit theory construct does. Therefore, given the considerable overlap between these two belief systems, found in both the empirical literature as well as theoretical works, it is possible that epistemic beliefs may be linked with the same meaning system that weaves the implicit theory construct together with motivation and other aspects of cognition.

Finally, modeling these two beliefs together to show their relationships to science achievement and motivation not only makes theoretical sense, but it also makes practical sense. As mentioned earlier, two main goals of science education reform include targeting students' beliefs that they possess the abilities to do well in science, as well as the belief that scientific knowledge is complex, continually revised, and must be supported using multiple lines of empirical evidence. Therefore, by keeping beliefs about knowledge and knowing separate from beliefs about innate ability, the present study is in keeping with calls from educational psychologists to keep the two constructs conceptually pure. Moreover, in keeping with calls from the science education community, the present study models how beliefs about the nature of 
science and beliefs about science ability relate with each other and with science achievement and motivation.

\section{Group Differences in Implicit Theories of Ability and Epistemic Beliefs}

Some researchers have begun to uncover differences in students' implicit theories by gender and race/ethnicity. Dweck and her colleagues have suggested that girls, especially highachieving girls, tend to endorse more of a fixed view of ability than their male counterparts, especially in science (Dweck, 1986, 2007). Chen and Pajares (2010) also found that, when controlling for previous achievement, boys were more likely to endorse an incremental view of ability than were girls in a sample of Grade 6 science students. Why might there be this gender difference in conceptions of ability? For one, girls who have had a history of outstanding performance generally possess lower expectancies for success do not prefer novel or difficult tasks, and display maladaptive beliefs and behavior patterns such as giving up prematurely, attributing failures to lack of ability rather than a lack of appropriate strategies (Licht \& Dweck, 1984; Parsons, Meece, Adler, \& Kaczala, 1982; Stipek \& Hoffman, 1980). Also, according to Dweck $(1986,2007)$, as students progress from one science class to the next, not only do students have to learn new skills in order to succeed, but they also have to accept and learn new conceptual frameworks. For example, learning chemistry requires understanding quite a different conceptual framework than does learning biology or Earth and Space science. Given girls' lower proclivity (especially high-achieving girls) to enjoy novel and challenging tasks, compared to boys, there may certainly be gender differences in science subjects with regard to conceptions of ability.

As for differences as a function of race/ethnicity, the research literature concerning implicit theories of ability is thin. However, there are empirical and theoretical reasons for why 
differences might emerge. For example, Good, Aronson, and Inzlicht (2003) showed that an intervention designed to manipulate students' implicit theories of ability within a computer skills class displayed differential effects depending on race/ethnicity. Specifically, Black students responded more positively to the incremental theory of ability treatment than did their White peers. Dweck and her colleagues have shown that a greater proportion of Asian students tend to fall into the incremental view of ability than do their Western counterparts (Chiu, Hong, \& Dweck, 1997; Kim, Grant, \& Dweck, 2000). They also found that Asian students who hold an incremental theory of ability tended to pursue tasks for the sake of appearing competent or shied away from tasks to avoid embarrassment (i.e., held performance goal orientations). This is in contrast to Western students who tended to hold learning goal orientations if they espoused an incremental theory of ability. These results suggesting that there are differences based on race/ethnicity are in contrast to others, however, who have found no differences in implicit theories of ability as a function of race/ethnicity (e.g., Chen \& Pajares, 2010).

Beyond empirical reasons for finding racial/ethnic differences in conceptions of ability, theoretical reasons exist too. First, Piaget and Garcia (1983/1989) suggested that different implicit theories may be emphasized by cultural factors. For example, Asian cultures, compared to Western cultures, have been hypothesized to emphasize a lack of effort and strategy-use when explaining failure (Chen, 2001; Hess, Chang, \& McDevitt, 1987; Holloway, Kashiwagi, Hess, \& Azuma, 1986). Because these attributions to either effort or ability are the very basis for students' implicit theories of ability, this belief might differ as a function of race/ethnicity. Also, as Sternberg and Grigorenko (2004) argued, culture shapes how one defines ability. Therefore, students' conceptions of ability do not develop in a vacuum, but rather are intertwined with the 
beliefs of the people within their cultural contexts (Ames \& Archer, 1987; Bempechat, Graham, \& Jimenez, 1999; Quihuis, Bempechat, Jimenez, \& Boulay, 2002).

Much research has been conducted examining gender differences in epistemic beliefs (e.g., Baxter Magolda, 1992; Belenky et al., 1986; Chen \& Pajares, 2010; Clinchy et al., 1985). These studies have shown mixed results—-some finding gender differences and others showing none. These discrepancies might have arisen from methodological and assessment differences. For example, Pintrich (2002) argued that the results using developmental models are usually qualitative, whereas the ones that treat epistemic beliefs as multidimensional examine the construct quantitatively using surveys. Not surprisingly, the qualitative studies find group-level differences whereas the quantitative ones usually do not. From a theoretical point of view, Pintrich (2002) proposed that gender or group-level differences in epistemic beliefs are likely not to arise because variables like gender and race/ethnicity serve only as proxies for more important factors. Pintrich proffered the example of gender orientation — the stereotypic beliefs about gender that students hold — as a better explanatory variable than gender (see Brosnan, 1998; Harter, Waters, \& Whitesell, 1997). Ultimately, Pintrich argued that there might be factors underlying surface-level characteristics like sex or ethnicity that explain group differences. This line of inquiry, however, has largely gone unexamined.

Despite Pintrich's (2002) proposal, Pintrich also conceded that such a proposition is highly contentious and was meant to spur further research on the topic. He also conceded that those who argue against his proposition do so on the grounds that explaining away differences in epistemic beliefs based on an underlying psychological factor might not be possible, given how individuals' gender and race/ethnicity may not be disentangled from their beliefs and the ways in which they think. This line of reasoning and its associated research (e.g., Karabenick \& Moosa, 
2005) suggest, as many have argued, that the individual cannot be separated from the cultural context (Bronfenbrenner, 1979; Quihuis et al., 2002; Vygotsky, 1978).

Finally, it is possible that there are developmental issues related to how implicit theories of ability and epistemic beliefs are related to motivation and achievement. Dweck and Leggett (1988) argued that implicit theories of ability can develop quite early. However, implicit theories alone do not have a primary effect on achievement and behavior. It is only when implicit theories become linked with a host of other beliefs such as goal orientations, beliefs about effort or failure, and perhaps beliefs about the nature of knowledge and knowing that they begin to exert their influence on academic outcomes (Dweck, 2002). According to Dweck, these beliefs do not form a coherent network until early adolescence. Therefore, it is possible that students in early middle school (like the youngest students in the present study) may differ from high school students in how strongly their conceptions of science ability are related to other motivation variables and beliefs about the nature of scientific knowledge and knowing.

Epistemic beliefs also may undergo developmental changes. Students are more likely to hold more sophisticated beliefs about knowledge and knowing as they get older and progress through more schooling (see Hofer \& Pinrich, 1997 for a review). However, Hofer and Pintrich also suggested that there may be a recursive effect whereby epistemic beliefs, after progressing in a more sophisticated direction, may revert back to less sophisticated stances during times of important transitions. Therefore, Grade 9 students, who are experiencing high school for the first time, may revert back to less sophisticated positions of epistemic beliefs that are more closely aligned with students in middle school. This notion has yet to be tested, however. 
With the above theoretical framework in mind, the purpose of the present study was to explore the individual belief profiles that naturally arise among middle school and high school science students. The relationships between these belief profiles to science achievement and other prominent motivation variables were also examined. The second purpose was to explore the demographic and developmental differences among the different belief profiles. The following research questions and hypotheses guided the present study:

1) What distinct student profiles emerge from measures of science epistemic beliefs and implicit theories of science ability? Based on previous cluster-analytic research using epistemic beliefs (Buehl \& Alexander, 2005), subgroups consisting of strongly adaptive and strongly maladaptive epistemic beliefs and implicit theories of ability were hypothesized to emerge. A number of subgroups consisting of mixed configurations of adaptive and maladaptive beliefs were also hypothesized to emerge.

2) How do these emergent student profiles relate to science achievement and other relevant motivation variables: Achievement goal orientations, self-efficacy, and achievement? Based on previous cluster-analytic research (Bråten \& Olaussen, 2005; Buehl \& Alexander, 2005), adaptive profiles (e.g., clusters that include such beliefs as incremental theory of ability and the belief that knowledge is constantly evolving rather than static) were hypothesized to be related to mastery goal orientations, higher self-efficacy, and science achievement. Student profiles that are less adaptive (e.g., clusters that include such beliefs as a fixed theory of ability and the belief that scientific experiments are simply projects people do in class rather than tools used to test hypotheses) were hypothesized to be related to performance goal orientations and lower self-efficacy and science achievement. 
3) How do these emergent student profiles differ by race/ethnicity, gender, and grade level? Based on the above review of literature on differences as a function of demographic variables, the researcher hypothesized that no differences would be found as a function of race/ethnicity and gender. With regards grade level, older students should have a greater probability of being in profiles with more sophisticated epistemic beliefs.

\section{Methodology}

\section{Participantsand Setting}

Participants were middle and high school science students $(\mathrm{n}=1225)$ from 2 public high schools and 1 public middle school in the same county of the Southeastern United States. The racial/ethnic demographics of the schools were as follows: 53\% White, 20\% Asian/Pacific Islander, $17 \%$ Black, and $8 \%$ Hispanic. Nine percent of the students were enrolled in Special Education, 3\% were enrolled in their school's English as a Second Language (ESOL) program, and $20 \%$ qualified for free or reduced price lunch.

Grade 6 students were enrolled in a class called Earth and Space Science, where they studied topics such as astronomy, the water cycle, and geology. Grade 9 students were enrolled in biology, where they learned topics such as genetics, cell biology, and natural selection. Grade 10 students were enrolled in chemistry, where they studied topics such as gas laws, chemical equations, and periodicity of the elements.

\section{Measures}

The variables in the present study have been used by researchers in investigations of science (e.g., Britner \& Pajares, 2001; Conley et al., 2004; Dweck, 1999; Elder, 2002; Zimmerman \& Bandura, 1994). All motivation variables in the present study were assessed using a 6-point Likert scale. For science self-efficacy, a rating of (1) represents a response of not 
at all confident and a rating of (6) represented a response of completely confident. For all other variables, a rating of (1) represents a response of complete disagreement and a (6) represents a response of complete agreement. Scores for each variable were calculated by obtaining a mean value. For academic achievement, midterm and end-of-term grades were collected in numerical form as the teachers marked them in their grade books. Grades range from 0-100.

Implicit theories of science ability. Items for the Implicit Theories of Science Ability scale were adapted from those used by Dweck (1999), and consist of six items that ask students specifically about their abilities in science rather than just their general intellectual abilities, as is the case with the original survey. The "self" form for children 10 years and older (Dweck, 1999) was used and worded to ensure that students focused on their ideas about their own science ability rather than on their ideas about people in general. Three items $(\alpha=.73)$ assessed students' fixed theory of science ability (e.g., "You have a certain amount of science ability, and you really can't do much to change it") and three others $(\alpha=.84)$ assessed their incremental theory (e.g., "No matter who you are, you can change your science abilities a lot").

Epistemic beliefs about the nature of science. Epistemic beliefs were assessed along the four core dimensions of the construct with a 26 -item instrument created and used by Conley et al. (2004). All questions were worded so that students focused specifically on the domain of science. The four core dimensions that were assessed are as follows: Source ( 5 items) is concerned with beliefs about knowledge residing in external authorities (e.g., "Whatever the teacher says in science class is true"). Certainty (6 items) represents the belief that questions in science have one correct answer (e.g., "All questions in science have one right answer"). Note that the source and certainty dimensions are stated from a naïve perspective. Development (6 items) is concerned with beliefs about science as an evolving and constantly changing body of 
knowledge (e.g., "Sometimes scientists change their minds about what is true in science").

Justification (9 items) is concerned with how students justify scientific claims, specifically as it relates to the role of scientific experiments (e.g., "Good answers are based on evidence from many different experiments"). Note that the development and justification dimensions are stated from a sophisticated perspective.

Conley et al. (2004) used this scale, which was adapted from Elder's (2002) original work, to assess students attending five elementary schools in the Southwest and reported the following coefficient alphas for the four dimensions, each one measured at two time points: Source (alphas were .81 (t1) and .82 (t2)); Certainty (alphas = .78 and .79); Development (alphas were .57 and .66); and Justification (alphas were .65 and .76). Mason, Gava, and Boldrin (2008) used the Certainty and Development sections of the questionnaire and obtained an overall reliability of $\alpha=.73$. In her original scale, Elder obtained coefficient alphas for the following three dimensions: Development (.67); Justification (.52); and Source (.64). A low coefficient alpha was obtained in Elder's original scale for the Certainty dimension $(\alpha<.40)$. For the present study, I obtained coefficients alpha of . 78 for the Development dimension, .86 for the Justification dimension, .74 for the Source dimension, and .73 for the Certainty dimension.

Science grade self-efficacy. Students' confidence in obtaining either an A, B, C, or D in their science class was assessed using a 4-item instrument (e.g., "How confident are you that you can get a grade of "C" or better in science this semester?"). Students provided a rating for each of the four grades mentioned above. When researchers have used this scale in the past they have obtained coefficient alphas ranging from .85 to .91 (e.g., Britner \& Pajares, 2001, 2006, 2009; Pajares, Britner, \& Valiante, 2000; Usher \& Pajares, 2008). A coefficient alpha of .85 was obtained in the present study. 
Science achievement goal orientations Science achievement goal orientations were assessed using a scale derived from the Patterns of Adaptive Learning Survey (PALS) (Middleton \& Midgley, 1997; Midgley et al., 2000) and adapted to reflect goals toward success in science class. Mastery goal orientations (five items; $\alpha=.85$ ) reflect striving to develop one's skills and abilities or advance one's learning and understanding of the material (e.g., "I like science assignments I can learn from, even if I make a lot of mistakes"). Performance approach goal orientations ( 5 items; $\alpha=.81$ ) entail focusing on attaining normative competence (e.g., "I want to do better than other students in my science class"). Performance avoid goal orientations ( 6 items; $\alpha=.80$ ) entail focusing on avoiding normative competence (e.g., "It's important to me that I don't look stupid in science class").

Demographics and achievement. Students self-reported their grade level, age, gender, and race/ethnicity. Achievement data, in the form of science grades were obtained from students' school records.

\section{Analysis}

For the first research question, exploring patterns of beliefs among students in science classes was the main concern. For this reason, a method of analysis that forms homogenous groups of students was employed. Latent Profile Analysis (LPA) is a latent variable mixture modeling technique used to identify groups of individuals that have similar values on the clustering variables, also called latent class indicators. In the present study, six latent class indicators were used: fixed theory of ability, incremental theory of ability, and the four dimensions of epistemic beliefs (Source, Justification, Certainty, and Development).

In uncovering the number of latent classes or profiles that emerge from the data, models with 2 through 7 latent classes ( $k=2$ to 7 ) were tested. For all models, variances were allowed 
to differ across each of the latent class indicators within a cluster, but were constrained to be equal across clusters. Additionally, all covariances were constrained to zero. Mplus (Muthén \& Muthén, 2010) was instructed to use 1000 random sets of starting values. After 20 iterations, the 100 best sets of starting values that were identified by the highest likelihood values were then selected for final optimization.

Question 2 examined how the emergent profiles relate to self-efficacy, achievement goal orientations, and science grade. Mplus 6 offers a function called AUXILIARY (e), which tests for the equality of means using variables that were not used in forming the profiles. This procedure employs a Wald chi-square test statistic to examine whether there is a statistically significant difference in means across profiles. Whereas in cluster analysis students are placed in discrete clusters or profiles, LPA builds in the fact that each individual has a probability associated with being in one profile. This takes into consideration the uncertainty of whether someone belongs in one group as opposed to another. These uncertainties are outputted by Mplus as posterior probabilities, which are then used in calculating the Wald chi-square statistic for equality of means.

Finally, to explore how the emergent student profiles differ by race/ethnicity, gender, and grade level, these variables were tested to examine whether they should be included in the model as a covariate that predicted latent class membership. To do this, Mplus's AUXILIARY (r) function was employed, which uses variables that were not used in forming the profiles to identify covariates that might be important predictors of the latent classes. This is done by using pseudo-class draws, which are the posterior-probability based multinomial logistic regressions of a categorical latent variable (latent class) on a set of covariates. After determining which of the above factors were significant predictors of latent class membership, the variables that 
significantly predicted membership into the model were included by regressing the categorical latent variable (latent class) onto the covariate(s). For race/ethnicity, because students could choose from among four categories (Asian, African American, Hispanic, and White), a variable called minority status was created such that students who indicated that they are Asian or White were classified as non-minority. Those who indicated that they are Hispanic or Black were classified as minority. This decision was made because Hispanic and Black students are typically underrepresented in scientific fields, whereas Asian and White students are not.

After determining which of the above factors were significant predictors of latent class membership, variables that significantly predicted membership into a latent class were included by regressing the categorical latent variable (latent class) on the covariates. Marsh et al. (2009) suggested that correlates should not be included in the model if they influence the definition of the latent groups. In addition, they strongly recommended that covariates be included in a model only if there is sufficient evidence to assume that the covariates are antecedent variables. For the present study, gender, race/ethnicity, and grade level were assumed to influence the way in which students are categorized into each profile. As has been shown previously, demographic variables such as race/ethnicity, gender, and age (grade level, in this case) are appropriate to include as covariates (Muthén, 2006).

\section{Results}

Means, standard deviations, and zero-order correlations for all variables are presented in Table 1. Consistent with recommended practices among LPA researchers (Lubke \& Muthén, 2005; Pastor et al., 2007) solutions with varying numbers of latent classes were tested and theory, past empirical evidence, characteristics of each profile (e.g., size), and interpretability 
were considered in arriving at a final solution. Table 2 displays the fit statistics for all models tested that aided in selecting the final model.

A 4-class model was chosen. Even though the 3-class model produced a non-significant result, suggesting a 2-class model, the 4-class model produced a number of interesting comparisons between profiles, as discussed later. Furthermore, the scree plot produced a noticeable elbow at the 4-class solution, suggesting that the BIC did not significantly improve from the 4-class model to the 5-class model, which was also confirmed by the LMR.

Because issues about the reliability of profiles are an important concern, the entire sample of middle and high school students was split in three different ways: 1) by random split-halves, 2) by grade level, and 3) by each individual school. When compared to the full 1225 -student sample, similar patterns were uncovered, thus providing evidence for the reliability of the groups. Therefore, considering the fit indexes, interpretability, and theory as guides, a 4-class model was chosen. As illustrated next, the profiles were differentiated by motivation, affect, and achievement in science, lending evidence for the validity of these profiles.

\section{Describing the Profiles}

The first aim of the present study was to identify profiles of implicit theories of ability and the four dimensions of epistemic beliefs, and to explore how these profiles related to science motivation and achievement. Table 3 shows the means and standard deviations for all variables used in forming the clusters. Figure 1 illustrates the four latent profiles, which are labeled according to the interpretations of findings. Figure 2 illustrates the relationships between these profiles to achievement goal orientations, self-efficacy and science grade.

The Thriving profile. At 576 students (47.0\%), this group represented the largest profile in the sample. These students reported very low agreement with a fixed theory of ability 
$(M=2.07)$ and very high agreement with an incremental theory of ability $(M=5.24)$. These Thriving students strongly rejected the notion that scientific knowledge resides only in external authorities like science teachers or professional scientists (considered a sophisticated belief). They also rejected the notion that problems in science only have one correct answer (considered a sophisticated belief). Thriving students also strongly believed that scientific knowledge is constantly evolving, and that experiments are used to support and evaluate scientific claims (both are considered sophisticated beliefs). More than any other group, Thriving students reported that they did science-related work for the sake of learning (mastery goal orientation; $M=4.46$ ), and were more confident in their capability to do well in science class (self-efficacy; $M=5.21$ ). At the end of the term, they earned higher science grades than their peers in any other group $(\mathrm{M}=86.5)$.

The Fixed/Sophisticated profile. Similar to their Thriving peers, the Fixed/Sophisticated profile ( $\mathrm{n}=194 ; 15.8 \%)$ reported what would be considered sophisticated stances about the nature of scientific knowledge and knowing. However, unlike their peers in the Thriving group, Fixed/Sophisticated students believed more strongly in the fixed nature of their science abilities. At the end of the term, these students earned fairly good grades $(\mathrm{M}=83.5)$, though slightly lower than their peers in the Thriving group. Fixed/Sophisticated students also disagreed that they did science work for the sake of learning (mastery goal orientations; $\mathrm{M}=3.53$ ), and were instead, more concerned with avoiding looking incompetent (performance avoid goal orientations; $M=3.24)$.

The Growth/Passive profile. At 382 (31.2\%), this was the second largest group of the sample. Growth/Passive students reported a belief that their capabilities in science could expand with effort (incremental theory of ability; $M=4.62$ ) and somewhat disagreed in a fixed view of 
ability $(M=3.25)$. Compared to their peers in the other groups, these students reported what would be considered the least sophisticated views (highest self-reported score) about the source $(M=3.58)$ and certainty $(M=3.29)$ of scientific knowledge. In other words, Growth/Passive students believed more strongly than their peers that only scientific authorities could know the one true answer to any scientific question or problem. Therefore, these students espoused a more passiveview about scientific knowledge, relative to their peers. Growth/Passive students were fairly mastery oriented in their goal pursuits $(M=4.12)$, but earned below average grades in science $(M=80.5)$, which were only higher than their peers in the Uncommitted profile.

The Uncommitted profile. The students of the smallest group in the sample $(n=73 ; 6 \%)$ were, on average, fairly hesitant in committing to a particular position on their beliefs about science ability and the nature of scientific knowledge and knowing. Compared to their peers, Uncommitted students were the least mastery oriented $(\mathrm{M}=3.02)$ and the most performance avoidant $(\mathrm{M}=3.40)$ in their goal orientations. They were the least confident in their capability to do well in science class (self-efficacy; $M=3.92$ ). At the end of the term, these students earned the lowest grade of all their peers $(M=74.7)$.

\section{Group Differences}

There were differences in the profiles as a function of minority status, grade level, and gender. Table 4 shows the probabilities of students being a member of a latent profile as a function of these variables. Figure 3 graphically illustrates these probabilities for grade level. Hispanic and African American students were less likely to be in the Fixed/Sophisticated and Thriving groups than were their Asian and White peers. And Hispanic and African American students were more likely to be in the Growth/Passive group than were their Asian and White peers. Girls were more likely to be members of the Fixed/Sophisticated group than were boys. 
Finally, older students were more likely to be members of the Fixed/Sophisticated group and much less likely to be in the Growth/Passive group than were their younger peers.

\section{Discussion}

The results of the present investigation illustrate the theoretical and practical significance of examining epistemic beliefs and implicit theories of ability along side of one another from a holistic analytical framework. The results refine the theoretical framework that undergirds the work in epistemic beliefs. Hofer and Pintrich (1997) suggested that, in an effort to keep the epistemic belief construct conceptually clean, beliefs about the nature of knowledge and knowing should be kept separate from beliefs about intellectual ability. At the same time, Schommer-Aikins (2004), in proposing the Embedded Systemic Model, argued that although these two beliefs are different constructs they might interact with each other. This implies that implicit theories cannot be excluded from consideration when thinking about epistemic beliefs especially in relation to motivation and achievement. Results of the present investigation suggest that, although these two beliefs are separate constructs, implicit theories of ability appear to be important enough to students' motivation and achievement that they cannot be ignored when investigating epistemic beliefs.

Compare, for example, the Thriving and the Fixed/Sophisticated groups. Although both groups were nearly identical in their sophisticated epistemic beliefs profile, the Thriving group reported significantly more adaptive self-efficacy and goal orientations. Although no causal claims can be made, this difference in motivation was related to the significant difference in their conceptions of ability. Also, although both groups of students seemed to perform above average in science their patterns of motivation were quite different. If implicit theories of ability had not been considered alongside of epistemic beliefs, the Fixed/Sophisticated group likely would have 
been grouped together with the Thriving group. In doing so, researchers would have missed the fact that although Fixed/Sophisticated students held sophisticated beliefs about the nature of scientific knowledge they believed that their abilities in science were static. This latter belief was related to this group's less adaptive motivational profile. As I discuss later, there are important theoretical and practical implications for this.

Another noteworthy comparison to make is between the Fixed/Sophisticated profile and the Growth/Passive profile. The interesting features to note here are that the Growth/Passive students, compared to their Fixed/Sophisticated peers, reported that they were more likely to approach tasks in science for the sake of learning (mastery goal orientation). This is in line with Dweck and Leggett's (1988) hypothesis that incremental views of ability are related to mastery goal orientations. However, Fixed/Sophisticated students were significantly more confident in their capabilities to perform well in science class (self-efficacy), and at the end of term Fixed/Sophisticated students earned significantly higher grades than did their Growth/Passive peers.

Although Dweck and her colleagues report that a Fixed theory is less adaptive than an incremental theory, there are some times when a Fixed theory might be related to higher selfefficacy and achievement (Dweck, Chiu, \& Hong, 1995). One possibility is that students who have a sophisticated understanding of science and have performed well in the past may believe that their high science abilities are an innate and unchanging trait. Such a belief could very well lead to a firm sense of efficacy that they can succeed in science. This result points to the possibility that implicit theories, as Dweck and her colleagues have consistently shown, are tied specifically to motivation, but that epistemic beliefs may be less strongly related to motivation. 
As discussed in more depth later, epistemic beliefs might, however, be tied to self-regulated learning and metacognition, and ultimately to achievement.

It may be, as suggested by Dweck and her colleagues (e.g., Dweck, Chiu, \& Hong, 1995; Molden \& Dweck, 2006), that there are other meaning systems besides beliefs about ability. Molden and Dweck suggested that these other belief systems may form "organized systems, attract allied goals, and begin to exert systemic influence" (p. 201). Epistemic beliefs may be one of these meaning systems in which particular allied goals are formed around them, as was suggested by Hofer and Pintrich (1997) in their seminal review. However, whereas implicit theories seem to be more tightly connected to motivation, it could be that epistemic beliefs are more tightly connected to other aspects of cognition. Some have suggested that epistemic beliefs may be core features of self-regulation (Muis, 2008) and metacognition (Hofer, 2004). Therefore, if epistemic beliefs form meaning systems around allied goals, it may be that, for students who believe that the best way to know whether something is true in science is simply to ask the teacher, these students may organize their goals for learning around such a belief and therefore find it irrelevant to do any further investigations into the matter. This kind of meaning system is quite different from students who believe that researching different sides to a scientific question and making a decision based on credibility of evidence is the best way to know whether something is true.

One way in which epistemic beliefs may be conceptualized to operate as a type of meaning system is to take the approach hypothesized by Dweck, Chiu, and Hong (1995). The authors argued that metaphysical systems can be portrayed as being built around either static objects or dynamic and evolving processes. In the static meaning system students emphasize "measurement of enduring properties" (p. 327), but in the dynamic and evolving meaning system 
"the emphasis is on understanding and influencing processes in evolving systems" (p. 327). The authors also argued that a moderator variable, confidence, helps predict students' subsequent behavior and beliefs. With regard to students' beliefs about the nature of scientific knowledge and knowing, the four dimensions of the construct are quite amenable to this conceptualization. For example, students who believe that scientific knowledge is isolated from other fields of knowledge, and that there is only one "correct" answer to scientific questions may approach science in different ways, depending on their self-efficacy to learn science. Students who believe in a single isolated answer in science, but who do not possess the sense of efficacy to learn science, may believe that the best source of knowledge resides in the teacher (an external authority). But the student who is self-efficacious about learning science may approach the task of finding the correct answer, not by asking the teacher, but by examining arguments from several competing sources and then weighing the evidence to make a final decision on the correct answer. Therefore, self-efficacy might well play a moderating role in how epistemic beliefs relate to academic outcomes. Future research could explore this possibility.

\section{Implications for Practice}

There are also practical implications for the results of the present study. This idea of incorporating epistemic beliefs with implicit theories to understand science learning and motivation is a common theme in many policy documents that call for reforming science education. For example, according to the National Academy of Sciences' Committee on Science, Engineering, and Public Policy (2011), one of the crucial aspects of strengthening the workforce in Science, Technology, Engineering, and Mathematics (STEM) is to cultivate certain Habits of Mind during K-8 science education. These habits of mind include four strands: (1) understanding scientific explanations; (2) generating scientific evidence; (3) reflecting on science 
knowledge; and (4) participating productively in science. At the heart of these four strands, is a notion of understanding the nature of scientific knowledge and knowing. For example, the third strand, reflecting on science knowledge, includes the idea that, "proficient learners understand that scientific knowledge builds on itself and can be revised over time" (p. 241). However, cultivating a sophisticated view about the nature of scientific knowledge and inquiry is only part of the equation. The Committee noted that, "there is a significant attrition from STEM majors at the end of the freshman year in college ... and those who switch [majors] tended to blame themselves and their abilities when they encountered difficulties" (p. 244).

\section{Group Differences in the Profiles}

The profiles differed as a function of minority status, gender, and grade level. As expected, students in higher grade levels reported more sophisticated epistemic beliefs than did their younger peers. This was clear with the Fixed/Sophisticated versus the Growth/Passive students. Grade 6 students were nearly 2.5 times more likely to be in the Growth/Passive group than were their high school peers. In contrast, high school students were 1.8 times more likely to be in the Fixed/Sophisticated group than were their Grade 6 peers. Because this was a crosssectional study, the data do not reveal the reasons for why this may be happening. However, the present study does support past empirical results showing that there is a developmental trend such that older students report more sophisticated epistemic beliefs (Pintrich, 2002). One caution regarding this grade level difference should be noted, however. Because grade level and science subject are confounded in the present study, the patterns described may not have arisen from differences in age, but rather differences in science subject studied. Unfortunately, there is no realistic way to resolve this. 
The present study suggested that there were important differences in the profiles as a function of race/ethnicity, contrary to Pintrich's (2002) hypothesis about epistemic beliefs, and Dweck's (2002) suggestion about implicit theories. White and Asian students were over 1.5 times more likely to be in the Fixed/Sophisticated group than were their Hispanic and African American peers. This suggests that Asian and White students, compared to Hispanic and African American students, hold more sophisticated views about the nature of scientific knowledge, although they are also more likely to believe in the fixed nature of ability.

This partially supports findings from Chen and Pajares (2010), who found that epistemic beliefs, but not implicit theories, differed as a function of race/ethnicity. Because Chen and Pajares investigated these relations from a variable-centered perspective, it could be that implicit theories of ability alone do not differ as a function of race/ethnicity, but when combined with epistemic beliefs in a person-centered approach, differences do arise. This illustrates why person-centered and variable-centered analyses can complement each other. In the present study, performing a t-test to test for mean differences between Hispanic and Black students versus Asian and White students revealed some more information. This analysis revealed that there were no differences between boys and girls with respect to incremental or fixed views of ability. There were, however, differences as a function of race/ethnicity. Hispanic and Black students reported significantly less sophisticated views about the development, justification, and certainty of scientific knowledge than did their Asian and White peers. Therefore, racial/ethnic differences in the profiles likely arose because of differences in epistemic beliefs rather than from implicit theories, reinforcing what Chen and Pajares (2010) found.

Finally, with regard to gender, the results suggest that gender is an important factor in how students view the nature of scientific knowledge and their beliefs about intellectual ability. 
Girls were more than twice as likely to be in the Fixed/Sophisticated group than were their male peers. This finding supports past empirical evidence showing that girls hold more fixed views about ability than do boys (see Dweck, 1999, 2002 for reviews). A t-test exploring mean differences by gender revealed that the gender differences between these two profiles were likely due to differences in epistemic beliefs rather than in implicit theories, as there were no gender differences in the sample with incremental or fixed views of ability. This also reinforces findings from Chen and Pajares (2010) about gender differences with implicit theories.

Two notes should be made before concluding. First, designating beliefs as either sophisticated or naïve is a product of Western thought (Hofer, 2006). There is still much more work that needs to be done to explore the contextually and culturally situated nature of epistemic beliefs. If, as I suggested earlier, researchers conceptualize epistemic beliefs as a meaning system whereby beliefs about knowledge and knowing are viewed on a continuum from static objects to dynamic and evolving processes, a similar nomenclature may be adopted. Fixed beliefs about the source of knowledge, for example, could mean that students believe that scientific knowledge is located in a fixed location-external authorities. A dynamic view of the source of scientific knowledge could mean that students view knowledge as coming from a multiplicity of sources, both external to the self and internal, and that this dynamic process of checking external sources' claims with one's own understandings and evidence can help produce a deeper understanding of science. This appears to be a fruitful direction for future research.

The second note to be made is that person-centered analyses, despite the nomenclature, are still averages of a group of people. In variable-centered approaches, all participants' scores are averaged. Person-centered analyses help in the sense that there is the assumption that there are multiple subcommunities (profiles) of students, each with different measurement errors and 
clustering properties (i.e., unobserved heterogeneity). However, groups are still averages of many students. Therefore, even within one group, there may be variability. The fact that the profiles differed on a variety of external variables, though, provides evidence that such variability was probably minimal.

\section{Conclusion}

Teachers who encourage their students to refine their beliefs about the nature of scientific knowledge may be facilitating their students' understanding of the epistemological assumptions of science. But an equally important goal is to develop students' belief that doing science is well within their capacity. The current push in science education reform to teach students about the nature of science may facilitate students' competence in understanding and doing science. However, for adolescents to persist through difficulties in science and ultimately to remain within the STEM pipeline, they need to possess the habits of mind mentioned by the Committee on Science, Engineering, and Public Policy (2011). Therefore, in addition to teaching students about the epistemological assumptions of science, teachers would do well to emphasize the incremental nature of ability and the self-regulatory processes like hard work and effective strategies that are the hallmark of those who succeed in science-related fields. 


\section{References}

Ames, C., and Archer, J. “Mothers' Beliefs About the Role of Ability and Effort in School Learning.” Journal of Educational Psychology, 1987, 71, 409-414.

Anderson, C. A. (1995). Implicit theories in broad perspective. Psychological Inquiry, 6, 286289.

Aronson, J., Fried, C. B., \& Good, C. (2002). Reducing the effects of stereotype threat on African American college students by shaping theories of intelligence. Journal of Experimental Social Psychology, 38, 113-125.

Bandura, A. (1997). Self-efficacy: The exercise of control. New York: W.H. Freeman.

Baxter Magolda, M. B. (1992). Knowing and reasoning in college: Gender-related patterns in students' intellectual development. San Francisco: Jossey Bass.

Belenky, M. F., Clinchy, B. M., Goldberger, N. R., \& Tarule, J. M. (1986). Women's ways of knowing: The development of self, voice, and mind. NewYork: Basic Books.

Bempechat, J., Graham, S., and Jimenez, N. V. "The Socialization of Achievement in Poor and Minority Students: A Comparative Study.” Journal of Cross-Cultural Psychology, 1999, $30,139-158$.

Blackwell, L. S., Trzesniewski, K. H., \& Dweck, C. S. (2007). Implicit theories of intelligence predict achievement across an adolescent transition: A longitudinal study and an intervention. Child Development, 78, 246-263.

Bråten, I., \& Olaussen, B. S. (1998). The relationship between motivational beliefs and learning strategy use among Norwegian college students. Contemporary Educational Psychology, 23, 182-194. 
Bråten, I., \& Olaussen, B. S. (2005). Profiling individual differences in student motivation: A longitudinal cluster-analytic study in different academic contexts. Contemporary Educational Psychology, 30, 359-396.

Bråten, I., \& Strømsø, H. I. (2004). Epistemological beliefs and implicit theories of intelligence as predictors of achievement goals. Contemporary Educational Psychology, 29, 371-388.

Britner, S. L. (2007). Motivation in high school science students: A comparison of gender differences in life, physical, and Earth science classes. Journal of Research in Science Teaching, 45, 955-970.

Britner, S. L., \& Pajares, F. (2001). Self-efficacy beliefs, race, and gender in middle school science. Journal of Women and Minorities in Science and Engineering, 7, 271-285.

Britner, S. L., \& Pajares, F. (2006). Sources of science self-efficacy beliefs of middle school students. Journal for Research in Science Teaching, 43, 485-499.

Britner, S. L., \& Pajares, F. (2009). Science anxiety, self-efficacy, and self-concept of undergraduate biology students. In A. Selkirk \& M. Tichenor (Eds.), Teacher Education: Policy, Practice, and Research (pp. 251-264). New York: Nova Science Publishers.

Bronfenbrenner, U. (1979). The Ecology of Human Development. Cambridge, MA.: Harvard University Press.

Brosnan, M. J. (1998a). The implications for academic attainment of perceived genderappropriateness upon spatial task performance. British Journal of Educational Psychology, 68, 203-215.

Buehl, M. M., \& Alexander, P. A. (2005). Motivation and performance differences in students' domain-specific epistemological belief profiles. American Educational Research Journal, 42, 697-726. 
Butler, R. (1990). The effects of mastery and competitive conditions on self-assessment at different ages. Child Development, 61, 201-210.

Butler, R. (1999). Information seeking and achievement motivation in middle childhood and adolescence: The role of conceptions of ability. Developmental Psychology, 35, 146-163.

Chen, H. (2001). Parents' attitudes and expectations regarding science education: Comparisons among American, Chinese-American, and Chinese families. Adolescence, 36, 305-313.

Chen, J. A., \& Pajares, F. (2010). Implicit theories of ability of Grade 6 science students: Relation to epistemological beliefs and academic motivation and achievement in science. Contemporary Educational Psychology.

Chi, M. T., Glazer, R., and Farr, M. J. (eds). (1988). The nature of expertise. Hillsdale, NJ: Erlbaum.

Cleaves, A. (2005). The formation of science choices in secondary school. International Journal of Science Education, 27, 471-486.

Clinchy, B. M., Belenky, M. F., Goldberger, N., \& Tarule, J. M. (1985). Connected education for women. Journal of Education, 167, 28-43.

Conley, A. M., Pintrich, P. R., Vekiri, I., \& Harrison, D. (2004). Changes in epistemological beliefs in elementary science students. Contemporary Educational Psychology, 29, 186204.

Dweck, C. S. (1986). Motivational processes affecting learning. American Psychologist, 41, 1040-1048.

Dweck, C. S. (Ed.). (1999). Self-theories: Their role in motivation, personality, and development. Philadelphia: Psychology Press. 
Dweck, C. S. (2002). The development of ability conceptions. In A. Wigfield \& J. S. Eccles (Eds.), The development of achievement motivation. San Diego: Academic Press.

Dweck, C. S. (2007). Is math a gift? Beliefs that put females at risk. In S. J. Ceci \& W. M. Williams (Eds.), Why aren't more women in science? Top researchers debate the evidence(pp. 47-55). Washington, DC: American Psychological Association.

Dweck, C. S., Chiu, C. Y., \& Hong, Y. Y. (1995). Implicit theories and their role in judgments and reactions: A world from two perspectives. Psychological Inquiry, 6, 267-285.

Dweck, C. S., \& Leggett, E. L. (1988). A social cognitive approach to motivation and personality. Psychological Review, 95, 256-273.

Dweck, C. S., \& Master, A. (2009). Self-theories motivate self-regulated learning. In D. H. Schunk \& B. J. Zimmerman (Eds.), Motivation and self-regulated learning: Theory, research, and applications (pp. 31-51). New York: Taylor \& Francis.

Dweck, C. S., \& Molden, D. C. (2005). Self-theories: Their impact on competence motivation and acquisition. In A. J. Elliot \& C. S. Dweck (Eds.), Handbook of competence and motivation (pp. 122-140).

Dweck, C. S., \& Sorich, L. (1999). Mastery-oriented thinking. In C. R. Snyder (Ed.), Coping. New York: Oxford University Press.

Elby, A. (2009). Defining personal epistemology: A response to Hofer \& Pintrich (1997) and Sandoval (2005). Journal of the Learning Science, 18, 138-149.

Elder, A. D. (2002). Characterizing fifth grade students' epistemological beliefs in science. In B. K. Hofer \& P. R. Pintrich (Eds.), Personal Epistemology: The psychology of beliefs about knowledge and knowing (pp. 347-364). Mahwah, NJ: Lawrence Erlbaum Associates. 
Elliott, E. S., \& Dweck, C. S. (1988). Goals: An approach to motivation and achievement. Journal of Personality and Social Psychology, 54, 5-12.

Good, C., Aronson, J., \& Inzlicht, M. (2003). Improving adolescents'standardized test performance: An intervention to reduce the effects of stereotype threat. Journal of Applied Developmental Psychology, 24, 645-662.

Harter, S., Waters, P., \& Whitesell, N. (1997). Lack of voice as a manifestation of false selfbehavior among adolescents: The school setting as a stage upon which the drama of authenticity is enacted. Educational Psychologist, 32, 153-173.

Hess, R. D., Chang, C. M., \& McDevitt, T. M. (1987). Cultural variations in family beliefs about children's performance in mathematics: Comparisons among People's Republic of China, Chinese-American, and Caucasian_American Families. Journal of Educational Psychology, 79, 179-188.

Hofer, B. K. (2004). Epistemological understanding as a metacognitive process: Thinking aloud during online searching. Educational Psychologist, 39, 43-55.

Hofer, B. K. (2006). Personal epistemology and culture. In M. S. Khine (Ed.), Knowing, knowledge, and beliefs: Epistemological studies across diverse cultures (pp. 3-22). Berlin: Springer.

Hofer, B. K., \& Pintrich, P. R. (1997). The development of epistemological theories: Beliefs about knowledge and knowing and their relation to learning. Review of Educational Research, 67, 88-140.

Hofer, B. K., \& Pintrich, P. R. (Eds.). (2002). Personal epistemology: The psychology of beliefs about knowledge and knowing. Mahwah, NJ: Erlbaum. 
Holloway, S. D., Kashiwagi, K., Hess, R. D., hiroshi, A. (1986). Causal attributions by Japanese and American mothers and children about performance in mathematics. International Journal of Psychology, 21, 269-286.

Hong, Y. Y., Chiu, C. Y., Dweck, C. S., Lin, D. M. S., \& Wan, W. (1999). Implicit theories, attributions, and coping: A meaning system approach. Journal of Personality and Social Psychology, 77, 588-599.

Jourden, F. J., Bandura, A., \& Banfield, J. T. (1991). The impact of conceptions of ability on self-regulatory factors and motor skill acquisition Journal of Sport \& Exercise Psychology, 13, 213-226.

Kaplan, A., Katz, I., \& Flum, H. (2012). Motivational theory in educational practice: Knowledge claims, challenges, and future directions. In K. R. Harris, S. Graham, and T. Urdan (Eds.), APA Educational Psychology Handbook: Vol. 2: Individual Differences and Cultural and Contextual Factors (pp. 165-194). Washington, DC: American Psychological Association.

Karabenick, S. A., \& Moosa, S. (2005). Culture and personal epistemology: U.S. and Middle Eastern students' beliefs about scientific knowledge and knowing. Social Psychology of Education, 8, 375-393.

Kuhn, D. (1991). The skills of argument. Cambridge, England: Cambridge University Press.

Li, L., \& Hser, Y. (2011). On inclusion of covariates for class enumeration of growth mixture models. Multivariate Behavioral Research, 46, 266-302.

Licht, B. G., \& Dweck, C. S. (1984). Determinants of academic achieve- ment: The interaction of children's achievement orientations with skill area. Developmental Psychology,20, 628-636. 
Lo, Y., Mendell, N., \& Rubin, D. B. (2001). Testing the number of components in a normal mixture. Biometrika, 88, 767-778.

Lubke, G. H., \& Muthén, B. (2005). Investigating population heterogeneity with factor mixture models. Psychological Methods, 10, 21-39.

McLachlan, G. \& Peel, D. (2000). Finite Mixture Models. New York: Wiley.

Magnusson, D., \& Stattin, H. (2006). The person in context: A holistic-interactionistic approach. In N. Eisenberg (Series Ed.) \& W. Damon \& R. M. Lerner (Vol. Eds.), Handbook of child psychology: Vol. 1. New York: Wiley.

Marsh, H. W., Craven, R. G., \& Debus, R. (1991). Self-concepts of young children 5 to 8 years of age: Measurement and multidimensional structure. Journal of Educational Psychology, 83, 377-392.

Marsh, H. W., Ludtke, O., Trautwein, U., \& Morin, A. J. (2009). Classical latent profile analysis of academic self-concept dimensions: Synergy of person- and variable-centered approaches to theoretical models of self-concept. Structural Equation Modeling, 16, 191225.

Mason, L., Gava, M., and Boldrin, A. (2008). On warm conceptual change: The interplay of text, epistemological beliefs, and topic interest. Journal of Educational Psychology, 100, 291309.

Middleton, M. J., \& Midgley, C. (1997). Avoiding the demonstration of lack of ability: An underexplored aspect of goal theory. Journal of Educational Psychology, 89, 710-718.

Midgley, C., Maehr, M. L., Hruda, L. Z., Anderman, E., Anderman, L., Freeman, K. E., et al. (2000). Manual for the patterns of adaptive learning scales (PALS). Ann Arbor, MI: University of Michigan. 
Molden, D. C., \& Dweck, C. S. (2006). Finding “meaning” in psychology. American Psychologist, 61, 192-203.

Molenaar, P. C. M., \& Campbell, C. G. (2009). The new person-specific paradigm in psychology. Current Directions in Psychological Science, 18, 112-117.

Molenaar, P. C. M., Sinclair, K. O., Rovine, M. J., Ram, N, \& Corneal, S. E. (2011). Analyzing developmental processes on an individual level using nonstationary time series modeling. Developmental Psychology, 45, 260-271.

Muis, K. R. (2008). Epistemic profiles and self-regulated learning: Examining relations in the context of mathematics problem solving. Contemporary Educational Psychology, 33, $177-208$.

Muis, Bendixen, \& Haerle (2006). Domain-generality and domain-specificity in personal epistemology research: Philosophical and empirical reflections in the development of a theoretical framework. Educational Psychology Review, 18, 3-54.

Muthén, B. O. (2006). Should substance use disorders be considered as categorical or dimensional? Addiction, 101 (Suppl. 1), 6-16.

Muthén, L. K., \& Muthén, B. O. (2010). Mplus user's guide: Sixth edition. Los Angeles, CA: Authors.

National Academy of Sciences (2011). Expanding underrepresented minority participation: America's science and technology talent at the crossroads. Washington, DC: National Academies Press.

National Research Council. (2000). Inquiry and the national science education standards: A guide for teaching and learning. Washington, DC: National Academy Press. 
National Research Council. (2007). Taking science to school: Learning and teaching science in grades K-8. Washington, DC: National Academy Press.

Nylund, K. L., Asparouhov, T., \& Muthén, B. O. (2007). Deciding on the number of classes in latent class analysis and growth mixture modeling: A Monte Carlo simulation study. Structural Equation Modeling: A Multidisciplinary Journal, 14, 535-569.

Pajares, F., Britner, S. L., \& Valiante, G. (2000). Relation between achievement goals and selfbeliefs of middle school students in writing and science. Contemporary Educational Psychology, 25, 406-422.

Pajares, F., \& Kranzler, J. (1995). Self-efficacy beliefs and general mental ability in mathematical problem-solving. Contemporary Educational Psychology, 20, 426-443.

Parsons, J. E., Meece, J. L., Adler, T. E, \& Kaczala, C. M. (1982). Sex differences in attributions and learned helplessness. Sex Roles, 8, 421- 432.

Pastor, D. A., Barron, K. E., Miller, B. J., \& Davis, S. L. (2007). A latent profile analysis of college students' achievement goal orientation. Contemporary Educational Psychology, $32,8-47$.

Perry, W. G. (1970). Forms of intellectual and ethical development in the college years: $A$ scheme. New York: Holt, Rinehart, and Winston.

Piaget, J., \& Garcia, R. (1983). Psychogenese et l'histoire des sciences [Psychogenesis and the history of the sciences]. Paris: Flamarion.

Pintrich, P. R. (2002). Future challenges and directions for theory and research on personal epistemology. In B. K. Hofer \& P. R. Pintrich (Eds.), Personal Epistemology: The psychology of beliefs about knowledge and knowing (pp. 389-414). Mahwah, NJ: Erlbaum. 
Qian, G. Y., \& Alvermann, D. (1995). Role of epistemological beliefs and learned helplessness in secondary-school students' learning science concepts from text. Journal of Educational Psychology, 87, 282-292.

Quihuis, G., Bempechat, J., Jimenez, N. V., \& Boulay, B. A. (2002). Implicit theories of intelligence across academic domains: A study of meaning making in adolescents of Mexican descent. New Directions for Child and Adolescent Development, 96, 87-100.

Robins, R. W., \& Pals, J. L. (2002). Implicit Self-Theories in the Academic Domain: Implications for Goal Orientation, Attributions, Affect, and Self-Esteem Change. Self \& Identity, 1, 313-336.

Schommer, M. (1990). Effects of beliefs about the nature of knowledge comprehension. Journal of Educational Psychology, 82, 498-504.

Schommer, M., Crouse, A., \& Rhodes, N. (1992). Epistemological beliefs and mathematical text comprehension: Believing it is simple does not make it so Journal of Educational Psychology, 84, 435-443.

Schommer-Aikins, M. (2004). Explaining the epistemological belief system: Introducing the embedded systemic model and coordinated research approach. Educational Psychologist, 39, 19-29.

Solomon, J., Duveen, J., Scot, L., \& McCarthy, S. (1992). Teaching about the nature of science through history: Action research in the classroom. Journal of Research in Science Teaching, 29, 409-421.

Sternberg, R. J., \& Grigorenko, E. L. (2004). Intelligence and culture: How culture shapes what intelligence means, and the implications for a science of well-being. Philosophical Transactions: Biological Sciences, 359, 1427-1434. 
Stipek, D. J., \& Daniels, D. (1988). Declining perceptions of competence: A consequence of changes in the child or the educational environment? Journal of Educational Psychology, 80, 352-356.

Stipek, D., \& Gralinski, J. H. (1996). Children's beliefs about intelligence and school performance. Journal of Educational Psychology, 88, 397-407.

Stipek, D. J., \& Hoffman, J. (1980). Development of children's performance-related judgments. Child Development, 51, 912-914.

Tabernero, C., \& Wood, R. E. (1999). Implicit theories versus the social construal of ability in self-regulation and performance on a complex task. Organizational Behavior and Human Decision Processes, 78, 104-127.

Usher, E. L., \& Pajares, F. (2008). Self-efficacy for self-regulated learning: A validation study. Educational and Psychological Measurement, 68, 443-463.

Vygotsky, L. (1978). Mind in society: The development of higher psychological processes. Cambridge, MA: Harvard University Press.

Wigfield, A., Eccles, J. S., Yoon, K. S., Harold, R. D., Arbreton, A., Freedman-Doan, K., \& Blumenfeld, P. C. (1997). Changes in children's competence beliefs and subjective task values across the elementary school years. Journal of Educational Psychology, 89, 451469.

Wood, P., \& Kardash, C. (2002). Critical elements in the design and analysis of studies of epistemology. In B. K. Hofer \& P. R. Pintrich (Eds.), Personal epistemology: The psychology of beliefs about knowledge(pp. 231-261). Mahwah, NJ: Erlbaum.

Zimmerman, B. J., \& Bandura, A. (1994). Impact of self-regulatory influences on writing course attainment. American Educational Research Journal, 31, 845-862. 


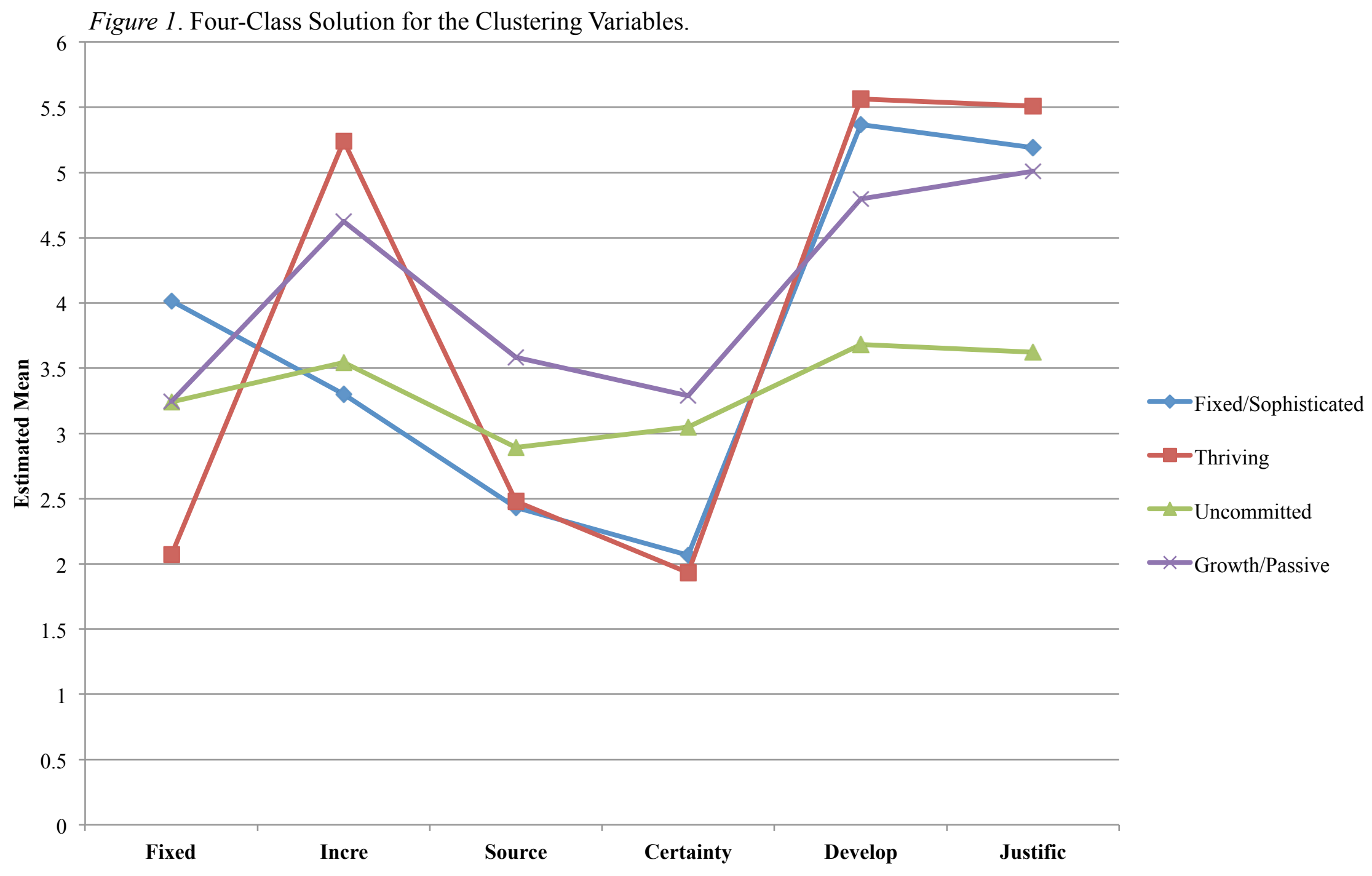

Note. Fixed/Sophisticated: $\mathrm{n}=194$ (15.8\%); Thriving: $\mathrm{n}=576$ (47.0\%); Uncommitted: $\mathrm{n}=73(6.0 \%)$; Growth/Passive: $\mathrm{n}=382(31.2 \%)$. 
Figure 2. Relation of the Four Latent Classes to Science Motivation and Achievement.

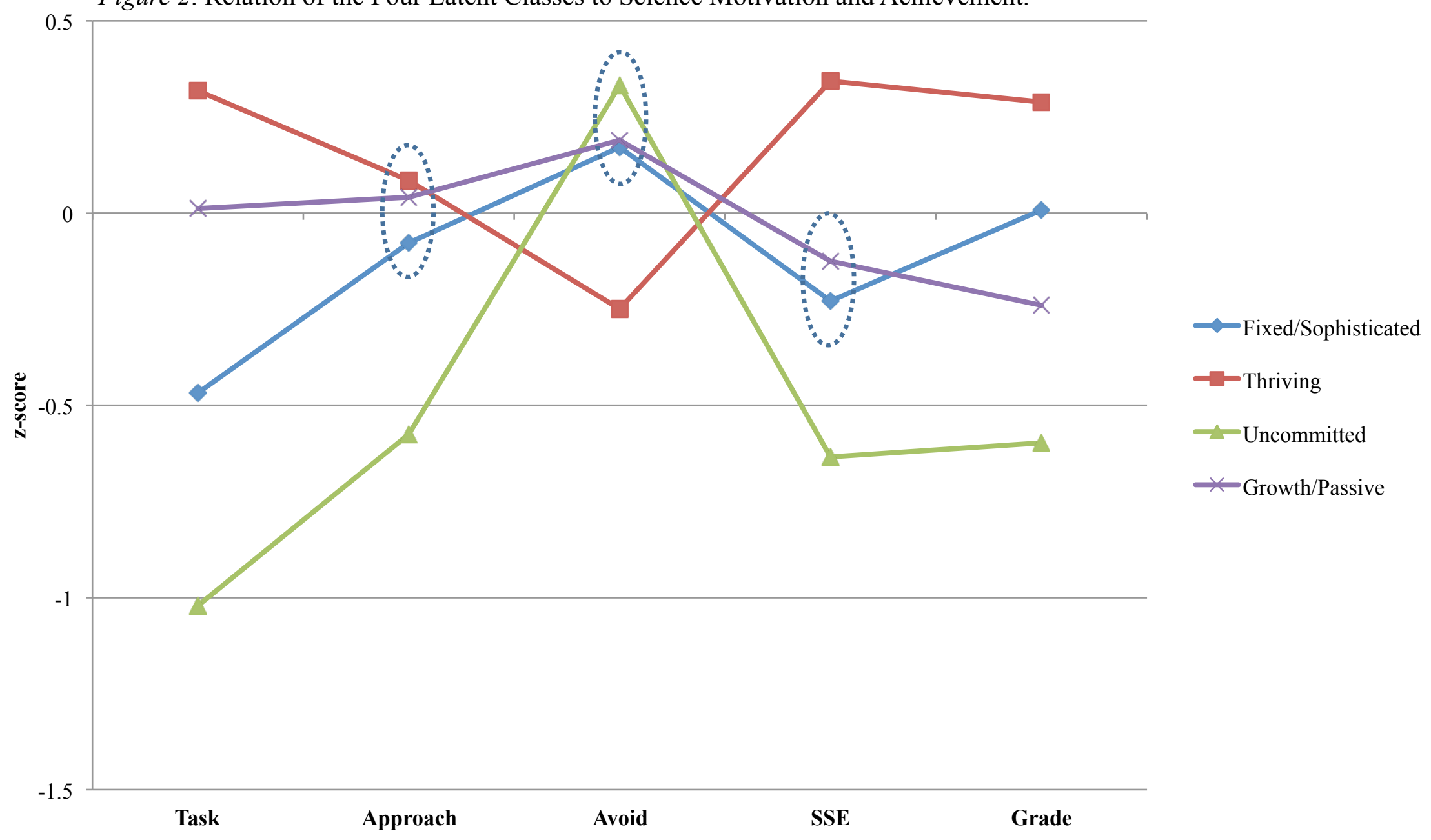

Note. Means in the same ellipses are not statistically different from each other (at the $p<.05$ ) level). Task=Task goal orientation; Approach=Performance approach goal orientation; Avoid=Performance avoid goal orientation; SSE=Science Self-Efficacy; Grade=Science Grade (out of 100 points). 
Figure 3. Estimated Probabilities of Being in a Latent Profile as a Function of Grade Level

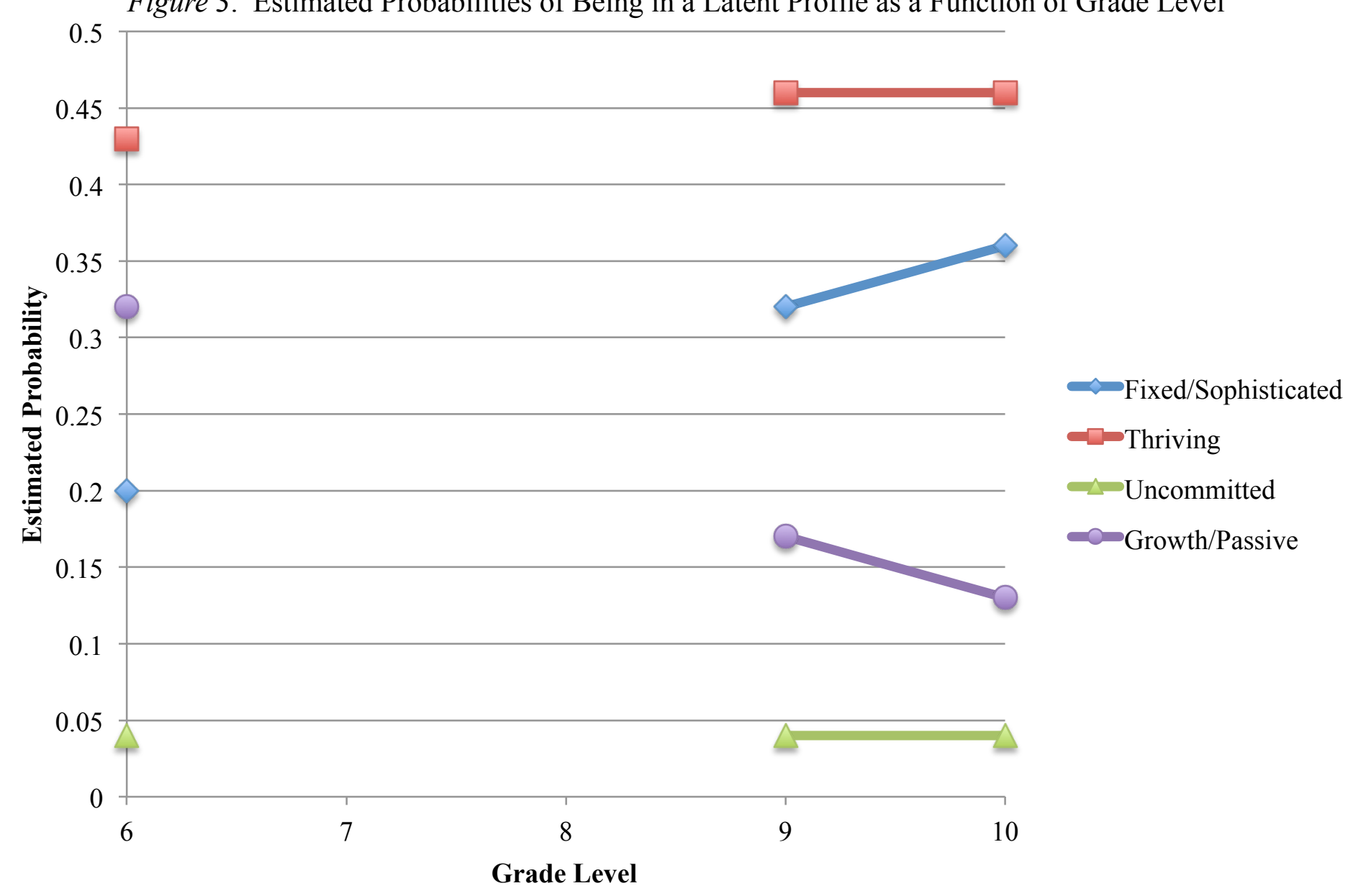


Table 1

Means, Standard Deviations, and Zero-Order Correlations of Variables in the Analysis

\begin{tabular}{|c|c|c|c|c|c|c|c|c|c|c|c|c|}
\hline Variable & M & SD & $\begin{array}{l}\text { Fixed } \\
\text { Theory }\end{array}$ & $\begin{array}{l}\text { Incremental } \\
\text { Theory }\end{array}$ & $\begin{array}{c}\text { Epist. } \\
\text { Beliefs } \\
\text { (Dvlpmt) }\end{array}$ & $\begin{array}{l}\text { Epist. } \\
\text { Beliefs } \\
\text { (Justif) }\end{array}$ & $\begin{array}{l}\text { Epist. } \\
\text { Beliefs } \\
\text { (Source) }\end{array}$ & $\begin{array}{l}\text { Epist. } \\
\text { Beliefs } \\
\text { (Certain) }\end{array}$ & $\begin{array}{c}\text { Self } \\
\text { Efficacy }\end{array}$ & $\begin{array}{c}\text { Mastery } \\
\text { Goal }\end{array}$ & $\begin{array}{c}\text { Perf. } \\
\text { Approach } \\
\text { Goal }\end{array}$ & $\begin{array}{l}\text { Perf. } \\
\text { Avoid } \\
\text { Goal }\end{array}$ \\
\hline 1. Fixed Theory & 2.8 & 1.2 & & & & & & & & & & \\
\hline 2. Incremental Theory & 4.6 & 1.2 & $-.58 * * *$ & & & & & & & & & \\
\hline 3. Epist. Beliefs (Dvlpmt) & 5.2 & 0.7 & $-.20 * * *$ & $.23 * * *$ & & & & & & & & \\
\hline 4. Epist. Beliefs (Justif) & 5.2 & 0.6 & $-.23 * * *$ & $.35 * * *$ & $.67 * * *$ & & & & & & & \\
\hline 5. Epist. Beliefs (Source) & 2.8 & 1.0 & $.15 * * *$ & 0 & $-.25 * * *$ & $-.08 * *$ & & & & & & \\
\hline 6. Epist. Beliefs (Certain) & 2.4 & 0.9 & $.28 * * *$ & -.05 & $-.43 * * *$ & $-.28 * * *$ & $.64 * * *$ & & & & & \\
\hline 7. Self-Efficacy & 4.9 & 1.2 & $-.25 * * *$ & $.28 * * *$ & $.24 * * *$ & $.31 * * *$ & -.05 & $-.17 * * *$ & & & & \\
\hline 8. Mastery Goal & 4.1 & 1.1 & $-.32 * * *$ & $.42 * * *$ & $.22 * * *$ & $.45 * * *$ & $.12 * * *$ & 0 & $.38 * * *$ & & & \\
\hline 9. Perf. Approach Goal & 4.3 & 1.1 & -.04 & $.12 * * *$ & $.15 * * *$ & $.27 * * *$ & $.14 * * *$ & .05 & $.10 * * *$ & $.25 * * *$ & & \\
\hline 10. Perf. Avoid Goal & 3.0 & 1.1 & $.28 * * *$ & $-.20 * * *$ & $-.11 * * *$ & $-.14 * * *$ & $.22 * * *$ & $.28 * * *$ & $-.21 * * *$ & $-.16 * * *$ & $.28 * * *$ & \\
\hline 11. Final Grade & 83.4 & 10.5 & $-.23 * * *$ & $.17 * * *$ & $.32 * * *$ & $.31 * * *$ & $-.09 * *$ & $-.28 * * *$ & $.60^{* * *}$ & $.23 * * *$ & $.13 * *$ & $-.16 * * *$ \\
\hline
\end{tabular}

Note. $\quad * p<.05 . \quad * * p<.01 . \quad * * * p<.001$. 
Table 2. Goodness of Fit Indexes

\begin{tabular}{ccccccc}
\hline $\begin{array}{c}\text { No. } \\
\text { Groups }\end{array}$ & Logliklihood & $\begin{array}{c}\text { No. Free } \\
\text { Parameters }\end{array}$ & BIC & $p$ LMR & Entropy & $\begin{array}{c}\text { Smallest Class Freq } \\
\text { (Rel. Freq) }\end{array}$ \\
\hline 2 & -9127 & 19 & 18389 & .0000 & .756 & $388(.317)$ \\
3 & -8880 & 26 & 17944 & .1712 & .793 & $77(.063)$ \\
4 & -8653 & 33 & 17540 & .0028 & .795 & $73(.060)$ \\
5 & -8547 & 40 & 17379 & .2145 & .810 & $41(.033)$ \\
6 & -8443 & 47 & 17221 & .1099 & .787 & $20(.016)$ \\
7 & -8374 & 54 & 17132 & .0387 & .771 & $17(.014)$ \\
\hline
\end{tabular}

Note. $\quad \mathrm{BIC}=$ Bayesian Information Criterion; $p \mathrm{LMR}=p$ values for the Lo-Mendell-Rubin likelihood ratio test for K versus K-1 classes. Smallest Class = size of the smallest latent class and the relative proportion. $N=1225$. 
Table 3

Means and Standard Deviations for Variables Disaggregated by Profile

\begin{tabular}{|c|c|c|c|c|c|c|c|c|}
\hline \multirow[b]{2}{*}{ Variables } & \multicolumn{2}{|c|}{$\begin{array}{c}\text { Fixed/Sophisticated } \\
n=194(15.8 \%)\end{array}$} & \multicolumn{2}{|c|}{$\begin{array}{c}\text { Thriving } \\
\mathrm{n}=576(47.0 \%)\end{array}$} & \multicolumn{2}{|c|}{$\begin{array}{c}\text { Uncommitted } \\
\mathrm{n}=73(6.0 \%)\end{array}$} & \multicolumn{2}{|c|}{$\begin{array}{c}\text { Growth/Passive } \\
\mathrm{n}=382(31.2 \%)\end{array}$} \\
\hline & $\mathrm{M}$ & $\mathrm{SD}$ & $\mathrm{M}$ & SD & $\mathrm{M}$ & $\mathrm{SD}$ & $\mathrm{M}$ & SD \\
\hline \multicolumn{9}{|l|}{ Clustering Variables $^{1}$} \\
\hline Fixed Theory of Ability & 4.02 & 2.0 & 2.07 & 1.7 & 3.24 & 1.8 & 3.25 & 1.9 \\
\hline Incremental Theory of Ability & 3.30 & 2.4 & 5.24 & 1.3 & 3.54 & 2.3 & 4.62 & 1.9 \\
\hline Epistemic Beliefs (Source) & 2.43 & 1.4 & 2.48 & 1.6 & 2.89 & 1.9 & 3.58 & 1.6 \\
\hline Epistemic Beliefs (Certainty) & 2.07 & 1.1 & 1.93 & 1.5 & 3.05 & 1.4 & 3.29 & 1.7 \\
\hline Epistemic Beliefs (Development) & 5.37 & 0.8 & 5.56 & 0.7 & 3.68 & 2.1 & 4.80 & 2.3 \\
\hline Epistemic Beliefs (Justification) & 5.19 & 0.8 & 5.51 & 0.6 & 3.62 & 2.5 & 5.01 & 2.1 \\
\hline \multicolumn{9}{|l|}{ Motivation $^{2}$} \\
\hline Self-Efficacy & $4.52 b$ & 1.4 & $5.21 \mathrm{a}$ & 1.1 & $3.92 \mathrm{c}$ & 1.5 & $4.68 \mathrm{~b}$ & 1.4 \\
\hline Mastery Goal & $3.53 \mathrm{c}$ & 1.2 & 4.46a & 1.1 & 3.02d & 1.1 & $4.12 b$ & 1.1 \\
\hline Performance Approach Goal & $4.23 \mathrm{a}$ & 1.1 & 4.41a & 1.2 & $3.60 \mathrm{~b}$ & 1.2 & $4.36 \mathrm{a}$ & 1.1 \\
\hline Performance Avoid Goal & $3.24 a$ & 1.2 & $2.75 b$ & 1.1 & $3.40 \mathrm{a}$ & 1.1 & $3.25 \mathrm{a}$ & 1.2 \\
\hline \multicolumn{9}{|l|}{ Achievement $^{3}$} \\
\hline Final Science Grade & $83.5 b$ & 11.5 & $86.5 a$ & 10.5 & 74.7d & 14.6 & $80.5 \mathrm{c}$ & 12.3 \\
\hline
\end{tabular}

Note. Means range from 1 to 6 for clustering and motivation variables, and 1-100 for achievement. Means for motivation and achievement (row) that are subscripted by different letters and in bold are statistically different $(\alpha<.05)$. Superscripts represent separate analyses. Sample size of each profile was based on students' most likely latent class membership. $\mathrm{N}=1225$. 
Table 4

Estimated Probabilities of Being in a Profile as a Function of Gender, Minority Status, and Grade Level

\begin{tabular}{|c|c|c|c|c|c|c|c|}
\hline \multirow[b]{2}{*}{ Profile } & \multicolumn{2}{|c|}{ Minority Status } & \multicolumn{3}{|c|}{ Grade Level } & \multicolumn{2}{|c|}{ Gender } \\
\hline & Non-Minority & Minority & 6 & 9 & 10 & Female & Male \\
\hline Fixed/Sophisticated & 0.20 & 0.12 & 0.20 & 0.32 & 0.36 & 0.20 & 0.11 \\
\hline Thriving & 0.43 & 0.34 & 0.43 & 0.46 & 0.46 & 0.43 & 0.45 \\
\hline Uncommitted & 0.04 & 0.06 & 0.04 & 0.04 & 0.04 & 0.04 & 0.06 \\
\hline Growth/Passive & 0.32 & 0.47 & 0.32 & 0.17 & 0.13 & 0.32 & 0.38 \\
\hline
\end{tabular}

Note. Probability values for minority status were calculated holding grade level constant at 6 and gender at 0 (female). Probability values for grade level were calculated holding minority status at 0 (non-minority) and gender at 0 . Probability values for gender were calculated holding minority status at 0 and grade level at 6 . Students self-reporting race/ethnicity as Asian or White were considered non-minority. 